\title{
Relevância clínica e frequência de padróes citoplasmático e pontilhado fino denso observados em FAN-HEp-2
}

\author{
Andréia Martini Pazini'1 , Juliana Fleck², Rosane Souza dos Santos², Sandra Trevisan Beck ${ }^{3}$
}

\begin{abstract}
RESUMO
Objetivos: O presente estudo procurou determinar a frequência e relacionar o título sorológico dos padrões de imunofluorescência para citoplasma celular e nuclear pontilhado fino denso com possível correlação clínica. Métodos: No período entre 2007 a 2009 foram avaliados os resultados de 2.788 testes sorológicos para pesquisa de autoanticorpos pela técnica de imunofluorescência indireta (IFI), utilizando como substrato células HEp-2, realizados no LAC-HUSM/ UFSM. Resultados: Entre as amostras analisadas, 1.998 resultaram não reagentes para a pesquisa de autoanticorpos. Entre as amostras reagentes $(n=790)$ foram encontradas $57(7,2 \%)$ amostras apresentando padrão de reatividade descrita como pontilhado fino denso (SFD) (3,8\%) ou fluorescência citoplasmática (Cit) (3,4\%). Nas amostras com padrão SFD $(\mathrm{n}=29)$, nove apresentaram título $<1 / 160$, onde apenas um paciente apresentava doença autoimune (DAI). Entre os pacientes com título $>1 / 160$ apenas um não apresentava DAI. Entre as amostras com padrão $\mathrm{Cit}(\mathrm{n}=27), 20$ apresentavam título $<1 / 160$, onde apenas oito não tinham DAI associada. Todos os outros 7 pacientes com título $>1 / 160$ tinham relato de DAI. Conclusão: Os resultados encontrados ratificam o valor de 1/160 como melhor ponto de corte para definição de presença de DAI, para qualquer um dos padrões de fluorescência avaliados. Contudo, deve-se prestar atenção a títulos inferiores, principalmente para IFI Cit, uma vez que apenas $40 \%$ não apresentavam relato de DAI presente.
\end{abstract}

Palavras-chave: anticorpos, autoimunidade, técnica indireta de fluorescência para anticorpo.

\section{INTRODUÇÃO}

A pesquisa de anticorpos antinúcleo (ANA) pela técnica de imunofluorescência indireta (IFI), também conhecido como fator antinuclear (FAN), em soro de pacientes com suspeita de doença autoimune (DAI), trata-se de um excelente exame de rastreamento de autoanticorpos. No início da década de 1950, realizava-se a IFI tendo como substrato corte ou imprint de fígado de roedores para a triagem de FAN no soro de pacientes com suspeita de DAI. ${ }^{1}$ A pesquisa positiva passou a indicar a possível presença de alguns autoanticorpos em pacientes com suspeita de lúpus eritematoso sistêmico (LES) e de outras DAI, como esclerose sistêmica (ES) e síndrome de Sjögren. Essa técnica, ao longo das últimas décadas, foi modificada de forma a conferir sensibilidade progressivamente maior 3 .

$\mathrm{Na}$ atualidade, a IFI utilizando célula de Epitelioma de Laringe Humana - HEp-2 (epitelioma humano tipo 2 - clone $\mathrm{CCl} 23 \mathrm{ATCC}$ ) praticamente substituiu a IFI utilizando imprint de células de roedores, devido a múltiplos fatores, entre o quais, a possibilidade de padronização universal, já que os vários laboratórios em todo o mundo passaram a utilizar o mesmo tipo de substrato. Atualmente, diversos fabricantes fornecem lâminas comerciais com células HEp-2 fixadas com excelente qualidade ${ }^{2,3}$ contribuindo para a aplicação técnica uniforme

\footnotetext{
Submetido em 01/10/2010. Aprovado, após revisão, em 23/11/2010. Declaramos a inexistência de conflito de interesse. Comitê de Ética n 0196.0.243.000-09. Universidade Federal de Santa Maria - UFSM.

1. Graduanda do Curso de Farmácia da UFSM

2. Mestre em Bioquimica Toxicológica pela UFSM; Farmacêutica-Bioquímica

3. Doutora em Ciências Farmacêuticas pela Universidade de São Paulo; Professora Adjunta da UFSM

Correspondência para: Departamento de Análises Clínicas e Toxicológicas, Centro de Ciências da Saúde - Prédio 26, sala 1205. Universidade Federal de Santa

Maria, Campus Universitário - Camobi. Santa Maria, RS. CEP: 971059-00. E-mail: andreiampazini@gmail.com
} 
entre os laboratórios de análises clínicas. ${ }^{4}$ Outro fator importante nesta substituição é a excelente visibilidade de múltiplos padrões de fluorescência ${ }^{5}$ e a oferta de uma diversidade de autoantígenos inerente a esse substrato. Como consequência, o teste de FAN passou também a apresentar maior sensibilidade e menor especificidade. ${ }^{4}$

Ultimamente, porém, têm sido reportados laudos laboratoriais com grande número de informações, que nem sempre traduzem de forma objetiva ou auxiliam determinar a condição de saúde de um paciente. $\mathrm{O}$ aumento na sensibilidade, no entanto, resultou em diminuição substancial na especificidade até mesmo para o diagnóstico de doença reumática autoimune, pois alguns indivíduos aparentemente hígidos (2\% a 4\%) passaram a apresentar resultados positivos pela técnica de FAN-IFI, ${ }^{2} \mathrm{o}$ que era extremamente raro com o teste das células LE.

Um dos principais padrões de imunofluorescência presente em amostras de indivíduos sadios é o pontilhado fino denso (SFD). Sua alta frequência em indivíduos com patologias não autoimunes torna o seu reconhecimento importante para que se possa apreciar adequadamente os achados do teste de FAN-HEp-2. ${ }^{6}$ Está bem demonstrada que a presença de autoanticorpos pode ser desencadeada transitoriamente por infecções, medicamentos e neoplasias. O padrão citoplasmático (Cit), que passou a ser relatado recentemente, na maioria dos casos, ainda não tem sua relevância clínica definida.

O presente trabalho teve por objetivo determinar a frequência e título de anticorpos do padrão de fluorescência nuclear fino denso e citoplasmático relacionando com a presença de DAI, determinando a relevância clínica dos resultados.

\section{MATERIAIS E MÉTODOS}

\section{Casuística}

Foram revisados os resultados de pesquisa de FAN por IFI realizada no Laboratório de Análises Clínicas (LAC) do Hospital Universitário de Santa Maria (HUSM) e analisados os prontuários dos pacientes que apresentaram positividade para os padrões SFD e Cit no período de janeiro de 2007 a março de 2010.

\section{Imunofluorescência indireta (IFI)}

A pesquisa de FAN por IFI em células HEp-2 (Hemagen Diagnóstica, Inc-Virgo ${ }^{\circledR}$ Products Division Columbia, Maryland 21045 USA) é realizada no LAC-HUSM de acordo com o seguinte protocolo: as células são incubadas com os soros dos pacientes diluídos em tampão salina fosfato $\mathrm{pH}$ 7,2 (PBS) por 30 minutos em câmara úmida à temperatura ambiente. Em seguida, as lâminas são lavadas duas vezes por 10 minutos em PBS e incubadas por 30 minutos com anticorpo secundário antigamaglobulina humana conjugada com isotiocianato de fluoresceína (FITC) em câmara escura à temperatura ambiente. Após a incubação, as lâminas são lavadas em PBS e montadas com glicerina tamponada e lamínula. A leitura é feita em microscópio de fluorescência, modelo Olympus BX 50 sob aumento de 500 vezes. A cada rotina de realização dos testes FAN são realizados controles internos negativos e positivos.

Os dados foram analisados utilizando-se estatística descritiva (média e frequencia [\%]). O presente estudo foi submetido e aprovado pelo Comitê de Ética em Pesquisa da UFSM sob o número CAAE 0196.0.243.000-09.

\section{RESULTADOS}

Entre os resultados FAN-HEp-2 avaliados $(\mathrm{n}=2.788)$ entre janeiro/2007 e março/2010 no LAC/HUSM, 1.998 (71,66\%) resultaram negativos para a pesquisa de autoanticorpos e 790 $(28,33 \%)$ tiveram resultados reagentes.

Dos 790 que tiveram positividade, 734 (92,92\%) apresentaram os seguintes padrões de fluorescência: nuclear homogêneo, nuclear pontilhado grosso, nuclear pontilhado fino, nuclear tipo membrana nuclear, nucleolar homogêneo, nucleolar pontilhado, nucleolar pontilhado pontos isolados, nucleolar pontilhado centromérico, nucleolar aglomerado e $56(7,1 \%)$ resultaram nuclear SFD ou Cit. Sendo que 29 amostras revelaram padrão nuclear SFD e 27 revelaram padrão Cit (Figura1).

Verificou-se que em $74 \%$ dos pacientes que apresentaram padrão Cit, os títulos encontrados foram baixos (1/40 e $1 / 80)$. Já aproximadamente metade $(55,2 \%)$ dos pacientes que demonstraram padrão SFD apresentou títulos elevados (1/320 e 1/640). À medida que os títulos aumentaram, diminuiu a prevalência do padrão citoplasmático, ao contrário do

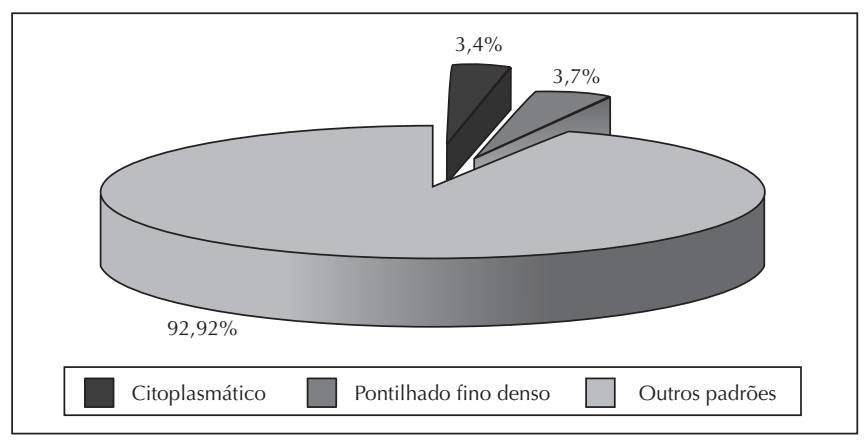

Figura 1

Frequência dos padrões de fluorescência do FAN-HEp-2 na população estudada. ${ }^{18}$ 
padrão SFD que predominou em pacientes com títulos mais elevados. (Figura 2)

Ao ser relacionado o título de IFI encontrado com evidência de DAI, pode ser observado que a prevalência de DAI ocorreu nos dois padrões em estudo, porém com diferentes níveis de reatividade (Tabela 1).

Os resultados relatados como padrão de fluorescência SFD, foram estratificados em conformidade com o título encontrado no soro de 29 pacientes classificados de acordo com a presença e ausência de evidência de autoimunidade (Figura 3).

Em relação ao padrão Cit foi possível verificar que em baixos títulos (1/40) foi encontrado um número significativo de DAI (Tabela 1). Contudo, pode ser observada uma menor especificidade nos títulos inferiores a 1/160, presentes nos soros de indivíduos sem evidência de DAI (Figura 4).

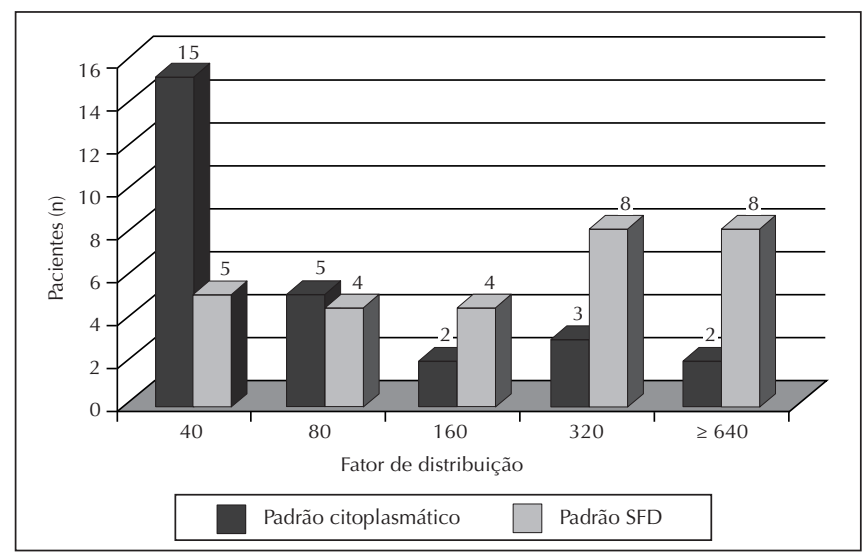

Figura 2

Frequência dos títulos de anticorpos e padrões de fluorescência de FAN na população estudada.

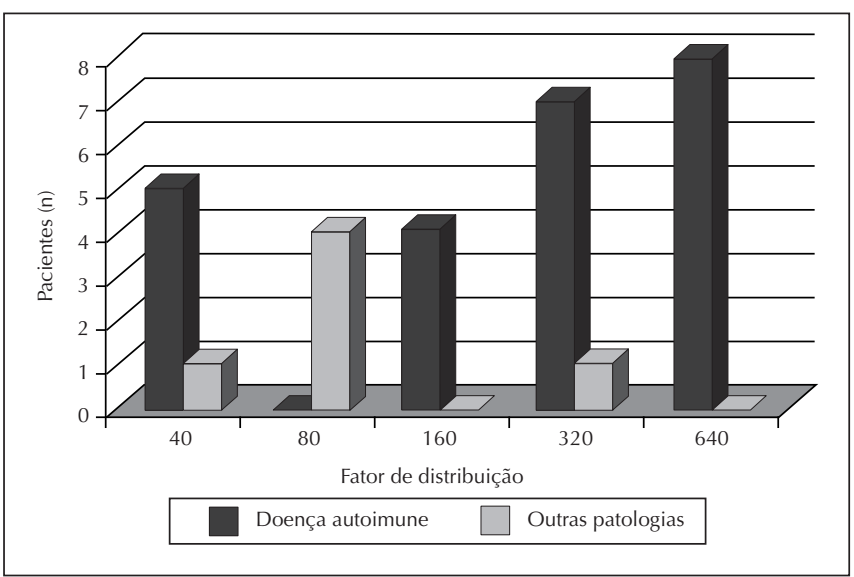

Figura 3

Frequência de doença autoimune (DAI) relacionada ao título de anticorpos encontrados no padrão de fluorescência pontilhado fino denso (SFD) no FAN em células HEp-2.

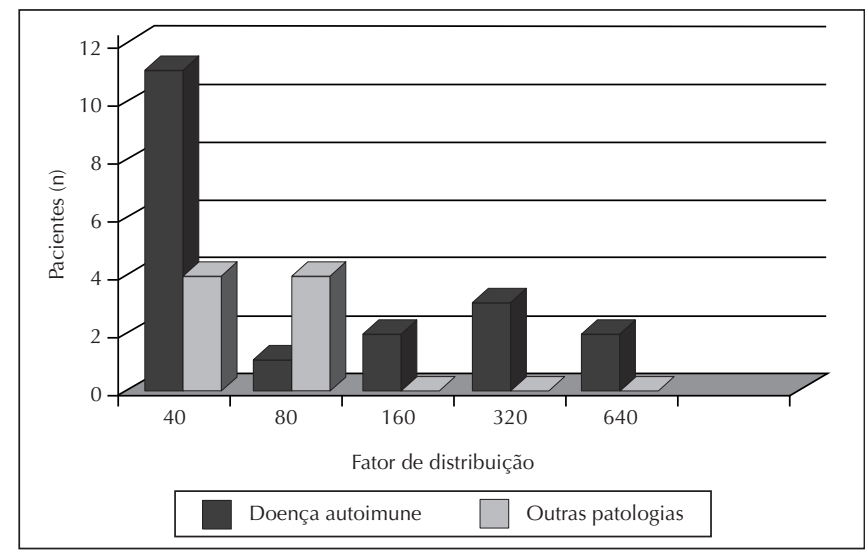

Figura 4

Frequência de doença autoimune (DAI) relacionada ao título de anticorpos apresentados pelo padrão de fluorescência citoplasmático (Cit) no FAN em células HEp-2.

\section{Tabela 1}

Doenças associadas aos padrões de fluorescência encontrados em FAN-HEp-2

\begin{tabular}{|c|c|c|c|c|c|c|c|c|}
\hline \multirow[b]{3}{*}{ Título } & \multicolumn{8}{|c|}{ Padrão } \\
\hline & \multicolumn{4}{|c|}{ Pontilhado fino denso } & \multicolumn{4}{|c|}{ Citoplasmático } \\
\hline & Doença autoimune & (n) & Outra condição & (n) & Doença autoimune & (n) & Outra condição & (n) \\
\hline $1 / 40$ & $\begin{array}{c}\text { AR } \\
\text { Pênfigo vulgar }\end{array}$ & $\begin{array}{l}1 \\
1\end{array}$ & $\begin{array}{c}\text { Estresse } \\
\text { Politraumatismo }\end{array}$ & $\begin{array}{l}1 \\
1\end{array}$ & $\begin{array}{c}\text { LES } \\
\text { AR } \\
\text { Cirrose. Biliar } \\
\text { Polimiosite }\end{array}$ & $\begin{array}{l}5 \\
5 \\
1 \\
1\end{array}$ & $\begin{array}{l}\text { Cardiopatia } \\
\text { Depressão } \\
\text { Artralgia }\end{array}$ & $\begin{array}{l}1 \\
1 \\
1\end{array}$ \\
\hline $1 / 80$ & Hepatite Al & 1 & $\begin{array}{l}\text { Herpes, } \\
\text { HIV, } \\
\text { Psoríase }\end{array}$ & $\begin{array}{l}1 \\
1 \\
1\end{array}$ & $\begin{array}{l}\text { Anemia hemolítica } \\
\text { Esclerodermia }\end{array}$ & $\begin{array}{l}2 \\
1\end{array}$ & Depressão & 1 \\
\hline$\geq 1 / 160$ & $\begin{array}{c}\text { LES } \\
\text { AR } \\
\text { Esclerodermia }\end{array}$ & $\begin{array}{c}14 \\
4 \\
2\end{array}$ & Câncer & 1 & $\begin{array}{c}\text { LES } \\
\text { AR } \\
\text { Hepatite AI }\end{array}$ & $\begin{array}{l}4 \\
2 \\
1\end{array}$ & & \\
\hline Total & 23 & & 6 & & 23 & & 4 & \\
\hline
\end{tabular}

LES: lúpus eritematoso sistêmico; AR: artrite reumatoide; Al: autoimune. 


\section{DISCUSSÃO}

A detecção de autoanticorpos no soro tem um papel prognóstico nas DAI, pois reflete a presença, a natureza e a intensidade da resposta autoimune. Existem mais de 100 diferentes tipos de doenças reumatológicas, sendo frequente a necessidade de diagnóstico diferencial entre as tais doenças. ${ }^{7}$

Houve uma acentuada evolução na interpretação dos padrões de IFI para detecção de autoanticorpos em células HEp-2 no transcorrer dos últimos anos. Essa metodologia apresenta a capacidade de rastrear uma grande variedade de anticorpos, proporcionando a localização e provável identidade do autoantígeno, porém apresenta como limitação variações na interpretação dos padrões de fluorescência. ${ }^{8}$ Tempos atrás, a maioria dos estudos estavam focados principalmente nos ANA, mas hoje acredita-se que anticorpos contra citoplasma, superfície celular, espaço intercelular e componentes da célula também são importantes no contexto das DAI. ${ }^{9}$

Conforme, o $3^{\circ}$ Consenso Nacional de Padronização de Laudos de FAN, estão descritas mais de 25 possibilidades de padrões de fluorescência. Cada um pode refletir uma dada expressão antigênica reconhecida pelo seu autoanticorpo..$^{10-12}$

Estudo pioneiro relacionado ao padrão SFD foi realizado por Ochs et al..$^{13} \mathrm{e}$ conforme já relatado por Laurino et al. ${ }^{14}$ há uma baixa prevalência deste padrão de fluorescência com placa metafásica positiva comparado aos outros existentes. Leser et al..$^{15}$ demonstraram que o padrão SFD apresentou alta taxa de associação com ausência de autoimunidade em títulos baixos, médios e altos.

Entre os padrões encontrados no presente estudo, a frequência do padrão SFD $(3,7 \%)$ e Cit $(3,4 \%)$ foi inferior ao relatado em outro serviço, onde a frequência foi de $6,3 \% \mathrm{e}$ $9 \%$, respectivamente. ${ }^{14}$ Provavelmente isso acontece devido à solicitação desse exame estar embasada no contexto clínico de cada paciente, tendo sido solicitado principalmente por reumatologistas do HUSM, o que levou a um número menor de detecção do padrão vinculado a inespecificidade. Tampoia et al. ${ }^{16}$ observaram que os reumatologistas solicitavam o FAN com uma maior frequência para pacientes que apresentavam dois ou mais critérios para classificação de DAI, ao contrário dos médicos de outras especialidades, que solicitavam esse exame para pacientes que apresentavam somente quadros inflamatórios.

Todos os indivíduos apresentam certo grau de autoimunidade fisiológica, a qual pode variar dependendo das sobrecargas a que o sistema imunológico seja exposto. Elevações transitórias dos títulos de FAN podem ocorrer em indivíduos com processos infecciosos agudos e com certos medicamentos como hidralazina, carbamazepina, hidantoína, procainamida, isoniazida, metildopa, dentre outros..$^{12}$ Provavelmente por este fator, alguns indivíduos com outras condições não autoimunes possam ter apresentado pesquisa de FAN reagente como demonstrado na Tabela 1. Não foi possível considerar a baixa reatividade exclusivamente como um fator normal, uma vez que a amostra analisada foi composta por soro de indivíduos que procuraram atendimento no HUSM, tendo seu exame realizado pelo laboratório central deste hospital, não podendo então ser excluída a presença de alguma enfermidade presente. Sabe-se que apesar da sensibilidade do teste de ANA ser bastante alta (quase $100 \%$ ) principalmente para o LES, sua especificidade pode ser baixa, principalmente quando a intensidade da reação é pequena (baixos títulos), fazendo com que seja detectado também em diferentes condições clínicas. ${ }^{17}$

O padrão nuclear SFD com placa metafásica positiva é descrito na literatura como tendo uma maior prevalência em pacientes sem evidências clínicas de DAI. ${ }^{18}$ Assim, Leser et $a l .{ }^{15}$ observaram que os padrões nuclear SFD, nuclear pontilhado reticulado e nuclear pontilhado fino associaram-se predominantemente a indivíduos sem qualquer evidência de DAI. Por outro lado, ao se conjugarem as informações de padrão de fluorescência e título, observaram que, para os padrões pontilhado fino e pontilhado grosso reticulado, a associação com ausência de DAI foi real apenas em títulos baixos. O mesmo não foi absolutamente verdadeiro para o padrão SFD, que apresentou alta taxa de associação com ausência de DAI em títulos baixos, médios e altos. ${ }^{15}$

Watanabe et al. ${ }^{6}$, em estudo sobre a frequência e o padrão do FAN por IFI em trabalhadoras hígidas de uma hidrelétrica, revelaram que o padrão SFD foi frequentemente encontrado naquelas com FAN positivo, aparecendo em títulos baixos, médios e altos. Esses resultados também puderam ser verificados no presente estudo, contudo, como pode ser observado na Figura 3, apesar de em títulos menores que 1/80 haver predomínio de outras condições não autoimunes, não é possível excluir totalmente a probabilidade, uma vez que cinco pacientes com DAI apresentaram título $1 / 40$ com esse padrão de fluorescência. Apenas em títulos maiores ou iguais a 1/640 não foram observados pacientes sem evidência de DAI.

Um segundo ponto a ser considerado é o título do FANHEp-2, muito embora seu valor seja relativo. Em geral, os portadores de DAI tendem a apresentar títulos moderados (1/160 e $1 / 320$ ) e elevados ( $\geq 1 / 640$ ), enquanto os indivíduos sadios com FAN-HEp-2 positivo tendem a apresentar baixos títulos $(1 / 80){ }^{2}$ Entretanto, é importante ter em mente que exceções de ambos os lados não são infrequentes. ${ }^{15}$ Dessa maneira, se faz relevante mencionar um estudo multicêntrico de reconhecida 
importância, realizado por Tan et $a l .{ }^{2}$ com indivíduos entre 20 e 60 anos. Entre os indivíduos hígidos, as seguintes percentagens de testes positivos foram encontradas: $1 / 40 \mathrm{em} 31,7 \%$ dos indivíduos, $1 / 80$ em13,3\%, 1/160 em 5,0\% e 1/320 em 3,3\%.

A relevância clínica do padrão Cit não se encontra ainda totalmente estabelecida. Segundo os pesquisadores Massabki et al. ${ }^{19} \mathrm{e}$ Eystathioy et al.$^{20}$, o padrão citoplasmático quando em títulos baixos ou moderados podem não ter relevância clínica definida. No entanto, o presente estudo verificou que pacientes com DAI como artrite reumatoide, LES, ES, poliomiosite apresentam esse padrão de fluorescência em baixos títulos.
Em conclusão, a minuciosa interpretação dos padrões de IFI exerce um papel fundamental na valorização dos resultados encontrados. O titulo do FAN-HEp-2 é um parâmetro de valor relativo, enquanto o padrão de fluorescência pode ter impacto mais decisivo. Os resultados encontrados no presente estudo ratificam o valor do título 1/160 como melhor ponto de corte para definição de presença de DAI, para qualquer um dos padrões de fluorescência avaliados. Contudo, deve-se prestar atenção a títulos inferiores, principalmente para fluorescência com padrão Cit, uma vez que apenas $40 \%$ não apresentavam relato de DAI presente. 


\section{REFERÊNCIAS}

\section{REFERENCES}

1. Coons AH, Kaplan, MH. Localization of antigen in tissue cells: II. Improvements in a method for the detection of antigen by means of fluorescent antibody. J Exp Med 1950; 91:1-13.

2. Tan EM, Feltkamp TE, Smolen JS, Butcher B, Dawkins R, Fritzler MJ et al. Range of antinuclear antibodies in "healthy" individuals. Arthritis Rheum 1997; 40(9):1601-11.

3. Nakamura RM, Bylund DJ, Tam EM. Current status of available standards for quality improvement of assay for detection of autoantibodies to nuclear and intracellular antigens. J Clin Lab Anal 1994; 8:360-8.

4. Dellavance A, Leser PG, Andrade LEC. Análise crítica do teste de anticorpos antinúcleo (FAN) na prática clínica. Rev. Bras. Reumatol 2007; 47(4):265-75.

5. Humbel R. Detection of antinuclear antibodies by immunofluorescent. In: van Verookij WM, RN, editor. Manual Biological Markers of Disease, 2ed, Netherkands, Kluwer Academic Publishers, 1993.

6. Watanabe A, Kodera M, Sugiura K, Usuda T, Tan EM, Takasaki Y. Anti-DFS70 antibodies in 597 healthy hospital workers. Arthritis Rheum 2004; 50:892-900.

7. Stinton LM, Fritzler MJ. A clinical approach to autoantibody testing in systemic autoimmune rheumatic disorders. Autoimmunity Reviews 2007; 77:77-84.

8. Pham BN, Albarede S, Guyard A, Burg E, Maisonneuve P. Impact of external quality assessment on antinuclear antibody detection performance. Lupus 2005; 14:113-9.

9. Stinton LM, Eystathioy T, Selak S, Chan EK, Fritzler MJ. Autoantibodies to protein transport and messenger RNA processing pathways: endosomes, lysosomes, Golgi complex, proteasomes, assemblyosomes, exosomes, and GW bodies. Clin Immunol 2004; 110(1):30-44.
10. Dellavance A, Gabriel Júnior A, Cintra AFU, Ximenes AC, Nuccitelli B, Mühlen CA et al. I Consenso Brasileiro de fator antinuclear em células Hep-2. J Bras Patol Med Lab 2002; 38:207-16.

11. Dellavance A, Gabriel Júnior A, Cintra AFU, Ximenes AC, Nuccitelli $\mathrm{B}$, Taliberti BH et al. II Consenso Brasileiro de fator antinuclear em células Hep-2. Rev Bras Reumatol 2003; 43:129-40.

12. Kavanaugh A, Tomar R, Reveille J, Solomon DH, Homburger HA. Guidelines for clinical use of the antinuclear antibody test and tests for specific autoantibodies to nuclear antigens. American College of Pathologists. Arch Pathol Lab Med 2000; 124:71-81.

13. Ochs RL, Stein TW, Peebles CL, Gittes RF, TAN EM. Autoantibodies in intersticial cystitis. J Urol 1994; 151:587-92.

14. Laurino CCFC, Lora PS, Brenol JCT, Grutcki DM, Xavier RM. Experiência da adoção do I e II Consensos Brasileiros de Fator Antinuclear por Imunofluorescência Indireta em Células HEp-2 em um hospital universitário. Rev Bras Reumatol 2009; 49(2):110-20.

15. Leser PG, Dellavance A, Barbosa SH, Guis G, Rodrigues SH, Sato EI et al. Distinctive features of antinuclear antibodies observed in health and in subjects with autoimmune rheumatic diseases. In: Conrad K, Bachmann MP, Chan EKL, Fritzler MJ, Humbel RL, Sack U et al., editors. From animal models to human genetics: research on the induction and pathogenicity of autoantibodies. Dresden: Pabst 2004; 4:493-510.

16. Tampoia M, Brescia V, Fontana A, Zucano A, Morrone LF, Pansini N. Application of a combined protocol for rational request and utilization of antibody assays improves clinical diagnostic efficacy in autoimmune rheumatic disease. Arch Pathol Lab Med 2007; 131:112-16.

17. Sinico RA, Bollini B, Sabadini E, Di Toma L, Radice A. The use of laboratory tests in diagnosis and monitoring of systemic lupus erythematosus. J Nephrol 2002; 15 Suppl 6:S20-7.

18. Dellavance A, Viana VS, Leon EP, Bonfa ES, Andrade LE, Leser PG. The clinical spectrum of antinuclear antibodies associated with the nuclear dense fine speckled immunofluorescent pattern. J Rheumatol $2005 ; 32: 2144-9$.

19. Massabki PS, Accetturi C, Nishie IA, da Silva NP, Sato EI, Andrade LE. Clinical implications of autoantibodies in HIV infection. AIDS 1997; 11(15):1845-50.

20. Eystathioy T, Chan EK, Tenenbaum SA, Keene JD, Griffith K, Fritzler MJ. A phosphorylated cytoplasmic autoantigen, GW182, associates with a unique population of human mRNAs within novel cytoplasmic speckles. Mol Biol Cell 2002; 13(4):1338-51. 